\title{
SiM
}

\section{Grazing for Biodiversity in Californian Mediterranean Grasslands}

\author{
By James W. Bartolome, Barbara H. Allen-Diaz, Sheila Barry, Lawrence D. Ford, \\ Michele Hammond, Peter Hopkinson, Felix Ratcliff, Sheri Spiegal, and Michael D. \\ White
}

\section{On the Ground}

- California's Mediterranean climate zone supports grasslands that are biologically diverse.

- Livestock grazing is being increasingly used to promote native species diversity at both the pasture and landscape scales.

- Several federally and state-listed vertebrates and insects respond positively to grazing to improve habitat by opening and lowering grassland vegetation. More work is needed on enhancement of native plants.

- Research results need to be more extensively applied, tested, and monitored under variable conditions.

Keywords: serpentine, vernal pools, native forbs, endangered species.

Rangelands 36(5):36-43

doi: 10.2111/Rangelands-D-14-00024.1

(c) 2014 The Society for Range Management

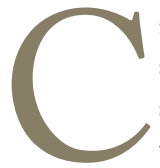

alifornia's diverse environments contribute to its status as an internationally recognized biodiversity hotspot (see Box 1) with more than 4,800 native plants, $29 \%$ of which are endemic to the state. Approximately 1,000 native vertebrates occur in the state, including 125 federally or state-listed species. ${ }^{1}$ The environments of Pleistocene Epoch, which began 1.8 million years ago and ended 10,000 years ago, were profoundly different from the prior 50 million years. More than 20 ice ages with associated ice caps and much lower sea levels dominated this epoch $90 \%$ of the time, alternating with short interglacial periods such as the present, which would be at an end soon except for anthropogenic global warming. California's ice-age climates supported more conifer forests, and although glaciation was extensive in the mountains and the rest of North America, much of California was an ice-free refugium for grassland and savanna plants and animals. Many of the surviving plant and animal taxa date from the origin of the true Mediterranean climate about two million years ago. ${ }^{2}$ California's endemic blue oak (Quercus douglasii Hook. \& Arn.), for example, likely retreated to small areas during the long glacial periods, then spread out with warming and became the most widespread and abundant savanna oak only during the past 10,000 years.

Californian rangelands during the Pleistocene supported a diverse fauna of grazing and browsing vertebrates, including camels, ground sloths, mammoths, mastodons, peccaries, and deer. We know that their numbers were high enough to support large populations of predators such as the North American lion, saber-toothed cat, short-faced bear, and dire wolf, as well as many scavengers such as numerous vulture species. These representatives of ice-age Pleistocene biodiversity survived many previous interglacials but not the Holocene. The oaks persisted, but only a handful of the large vertebrates did, including humans (Homo sapiens L.), who had joined the list about 14,000 years ago and may have contributed to the extinctions. Grazing pressure and native herbivore diversity both peaked during the most recent Pleistocene ice age, decreasing dramatically when humans arrived and the ice retreated 10,000 years ago. Native diversity in California decreased again with European settlement and the introduction of livestock and alien plants starting in 1769. The few remaining native vertebrate herbivores such as Tule elk (Cervus elaphus nannodes Merriam), pronghorn (Antilocapra americana Ord), and ground squirrels (Spermophilus spp.) were eliminated or reduced; the California grizzly (Ursus arctos californicus Merriam) and wolf (Canis lupus L.) were trapped, poisoned, and hunted to extinction; and alien plants spread rapidly. The evaluation of managed grazing effects on native species diversity should be viewed against this dramatic, intricate, and relatively recent background of changes in climate, human impacts, and grazing animals.

In this paper we examine the relationships between grazing and native species biodiversity for selected taxa, groups of species, or communities. For each example, we provide a brief 


\section{California's Mediterranean-Type Grasslands: A Hotspot of Biodiversity}

\section{Lawrence D. Ford}

Listed below are national and international reports recognizing California's Mediterranean-type grasslands as among the world's "hotspots" of native species rarity and richness, despite their general dominance by non-native species. Appreciating this paradox can aid communication between conservation biologists, environmental regulators, and ranchers about managing California rangelands for conservation and sustainable development.

\section{Description}

\section{Source}

\section{Designation of California grasslands among world hotspots}

The six recognized hotspots of highest native species rarity and richness in the United States include two regions of California within the Mediterranean climate zone (the San Francisco Bay area and the coastal and interior Southern California hotspots) that support grasslands.

The California Floristic Province ranks among the world's 25 hotspots of biodiversity for richness of native plants and vertebrate species and endemism and risk of extinction.

California's native grasslands rank among the 21 most-endangered ecosystems in the United States. The native prairies, other grasslands, and savannas, including those in California, are the most reduced ecosystems in terms of acres lost since European settlement.

\section{Temperate grassland biomes endangered}

Temperate grasslands and savannas are among the world's biomes that have suffered the most extensive habitat loss in terms of percent converted and are critically endangered (the highest crisis ranking).

\section{California grassland biodiversity statistics}

Currently 75 California grassland-associated native species, including 10 vertebrates, 14 invertebrates, and 51 plants, are listed as threatened or endangered under the federal Endangered Species Act.

The numbers of native animals and plants with federal, state, and/or other special status associated with California grasslands include 23 mammals, 18 birds, 9 amphibians, 5 reptiles, 46 invertebrates, and 479 plants (2006 data from California Natural Diversity Database and the California Native Plant Society's Electronic Inventory of Rare and Endangered Vascular Plants of California).

California's hardwood rangelands (including grasslands) provide habitat for more than 300 vertebrate wildlife species, more than 2,000 plant species, and $\sim 5,000$ insect species.

Stein, Kutner, and Adams $2000^{18}$

Myers et al. $2000^{19}$

Noss and Peters $1995^{20}$

Hoekstra et al. $2005,{ }^{21}$ Peart $2008^{22}$

\section{California habitat structural diversity and connectivity}

Grassland habitat structure affects diversity of micro-habitats available for different native animals and plants, including critical host plants, prey, and bare ground. As examples, the endangered Ohlone tiger beetle requires bare or sparsely vegetated soil surfaces for larval burrows, feeding, and adult mating and ovipositing, which can be maintained by grazing; and the threatened Bay checkerspot and other butterflies require host plants in openings that are maintained by grazing.

Grassland use changes, such as reduction or abandonment of livestock grazing on grasslands, reduced frequency of wildfire, reduced rancher stewardship, roadside pesticide use and scraping, and intensification of nearby agriculture, can reduce habitat diversity for native grassland species and lead to natural succession to woody vegetation; a useful indicator of grassland biodiversity is butterflies and other invertebrates that respond readily to changes in the structure of grassland habitat.

Habitat connectivity between undeveloped grassland sites in the highly developed San Francisco Bay region is a critical objective for the conservation of viable populations of numerous grassland dependent special-status species.

Jantz et al. $2007^{23}$

L.D. Ford, personal communication

Standiford, Klein, and Garrison $1996^{24}$

Knisely and Arnold 2013; ${ }^{11}$ Weiss, Wright, and Niederer $2007^{25}$

European Environment Agency $2013^{26}$

Penrod et al. $2013^{27}$ 
background, then summarize what is known about grazing effects (using published information about the role of grazing in managing native biodiversity) and make observations and recommendations relevant to grassland conservation.

\section{Grazing Effects on Grassland Biodiversity in the Californian Grassland}

Biodiversity is defined as the abundance and distribution of organisms. The most commonly measured metric for biodiversity used in environmental work is the number of species present or species richness. This measure is related to diversity and is relatively cheap to determine but does not tell the whole story. Knowing the distribution and origin of organisms is necessary to fully interpret the links between management, conservation, and ecosystem structure and function. It is also important to consider that the distribution of organisms can be evaluated at different spatial and temporal scales. The most relevant spatial scales for rangelands are pasture and landscape. ${ }^{3}$ The most important link of biodiversity to grazing is the response of organisms to modifications of their habitat.

Grazing and browsing of plants can be considered predation by herbivores. An important evolved ecosystem function, it transfers energy and nutrients captured by plants to higher trophic levels. ${ }^{4}$ The conflict between plant energy capture through leaves and grazing removal of those same leaves leads to important effects on biodiversity because materials pass through herbivores and affect habitat structure for both plants and animals. The grazing process and its management can be conveniently divided into intensity (how much), season (when), distribution (where), and frequency (how often). Understanding grazing effects on biodiversity requires carefully combining the multiple aspects of grazing with changes in habitat and biodiversity at multiple spatial and temporal scales. Researchers and land managers find it challenging to construct grazing strategies that favor native species, especially when multiple plant and herbivore species are considered. Some of this grazing in California's not-so-distant past was on today's native plants by camels and mammoths.

\section{Native Perennial Grasses}

No reliable records exist for the original California prairie, which is believed to roughly correspond in extent with current grasslands. When prairie ecologist Frederic Clements first visited California in 1917, he wrote that the original grassland must once have been dominated by native perennial bunchgrasses, which had been grazed out and replaced by annuals from the Mediterranean. This story, with little direct evidence, persists and has long dominated restoration of native plant biodiversity in California. We now know that this story is mostly incorrect. ${ }^{5}$ Phytoliths are small taxonomically distinctive silica particles prolifically produced by grasses that are preserved for millennia in soil. The application of phytolith analysis to archived grassland soils showed that perennial grasses were rare during the late Holocene, except along water courses and on coastal terraces. Elsewhere some areas were probably dominated by native grasses, usually on less fertile soils.

Not surprisingly, attempts to restore the supposed original native perennial grassland and its associated diversity using grazing management have met with mixed results in the Mediterranean climate zone. A summary of studies that investigated grazing for perennial grass restoration showed that the common native grasses responded idiosyncratically to grazing and burning, even when results were compared within coastal areas (where phytoliths show native perennials were common) and more inland sites., ${ }^{4,6}$ Attempts to enhance native plant species through management of season and frequency of grazing have not been effective. Reduction of residual dry matter through moderate intensity of use can help keep litter-dependent exotic grasses such as medusahead (Elymus caput-medusae [L.] and ripgut brome (Bromus diandrus Roth) at lower levels, but generally grazing appears to have little impact on diversity of native perennial grasses. Diversity is largely controlled by soil properties at the pasture scale and climate at the landscape scale. Successful restoration of diversity of native perennial grasses depends on identifying at the landscape scale where perennials were present (for example, coastal and stream terraces) and, at the pasture scale, areas of suitable soil properties with a seed source. The background level of grazing appears less important for biodiversity than abiotic influences.

\section{Native Annual Plants}

Botanical enthusiasts from around the world travel to California to experience its great diversity of wildflowers, but whether they experience the colorful blooms that make this hotspot famous depends on the timing and location of their visits. More than 2,400 annual forbs are native to California, and although the species richness of this group is high, the cover and density of most native forbs remain low unless specific environmental conditions occur. California's native annual wildflowers are highly influenced by the physical environment - for each ecological region, the climate dictates the suite of viable species, the arrangement of soil properties largely controls the spatial distribution of the viable species, and rainfall timing and amount drives the timing of germination and blooms. The variability of California's physical environment results in a wildflower species distribution that is spatially and temporally patchy. ${ }^{4}$ That situation is further complicated by the specific adaptations of these myriad species; for example, many of California's wildflowers can persist as seeds for decades or even centuries and will germinate and bloom only when weather conditions are right or after a fire. Detailed accounts written by Europeans suggest that this sporadic timing and patchy distribution of wildflower blooms was in effect before the widespread invasion of the highly successful grasses and forbs from the Old World, indicating that the ecological impacts of this still-continuing invasion must be determined on site- and time-specific bases. 
On the pasture scale, within a singular regional climate zone, particular soils have the capacity to sustain distinct assemblages of native wildflowers, and those wildflowers germinate and bloom only when the weather pattern is favorable. A recent meta-analysis identified trends in the effects of grazing on forbs in Mediterranean-climate Californian grassland. ${ }^{6}$ Those authors found that in response to grazing, native forb cover increased more in arid inland sites than it did in mesic coastal sites, especially when grazing occurred during the November to May wet season. On certain soils in arid inland sites, the positive response of native annual wildflowers to wet season grazing could be due to enhanced light for germination and growth (Fig. 1). For example, in the grasslands of low-elevation ( $200 \mathrm{~m}[660 \mathrm{ft}])$, sandy-textured soils on the alluvial fans of the southern San Joaquin Valley, native annual forb cover was positively correlated with low cover $(<5 \%)$ of ground litter cover during the growing season. ${ }^{4}$ Although this low litter situation could be achieved using a variety of methods (including mowing and burning) grazing is the most reliable and cost-effective tool for the extensive grasslands of the region.

\section{Vernal Pools and Serpentine Grasslands}

Scattered within the matrix of California's two main Mediterranean grassland types, pockets of specialized habitat make an outsized contribution to grassland landscape biodiversity, including numerous locally evolved endemic taxa. Serpentine grassland and vernal pools are two of the specialized habitats, and livestock grazing has been shown to protect plant and animal biodiversity in both.

Serpentine soil is inhospitable for plant growth; it has low levels of many important plant nutrients but is simultaneously high in magnesium and toxic heavy metals. Vernal pools form in small depressions that are underlain by impervious layers of clay or cemented hardpans. Winter rain collects in the depression and forms a pool; as the season progresses, the pool begins to dry and during the summer is typically bone-dry. Depending on the season, vernal pools are too wet for most upland plants or too dry for wetland plants - similar to serpentine soil, a difficult habitat. Unfortunately for native diversity, most historic vernal pools have been lost to urban and suburban development.

In both patchy habitats, plants and animals have evolved to tolerate the harsh, isolated conditions. There are many serpentine endemics, and several are federally listed. Endemic invertebrates such as the federally listed Bay checkerspot butterfly (Euphydryas editha bayensis Sternitzky) are also found exclusively in serpentine grasslands. ${ }^{7}$ In vernal pools, a highly specialized set of plants has evolved that can tolerate both aquatic and drought conditions. They typically germinate and begin to grow underwater, but their adult life generally occurs in much drier conditions. Endemic vernal pool tadpole and fairy shrimp species, several of which are federally listed, must also cope with desiccation for part of the year or longer. The federally listed California tiger salamander $(\mathrm{Am}-$

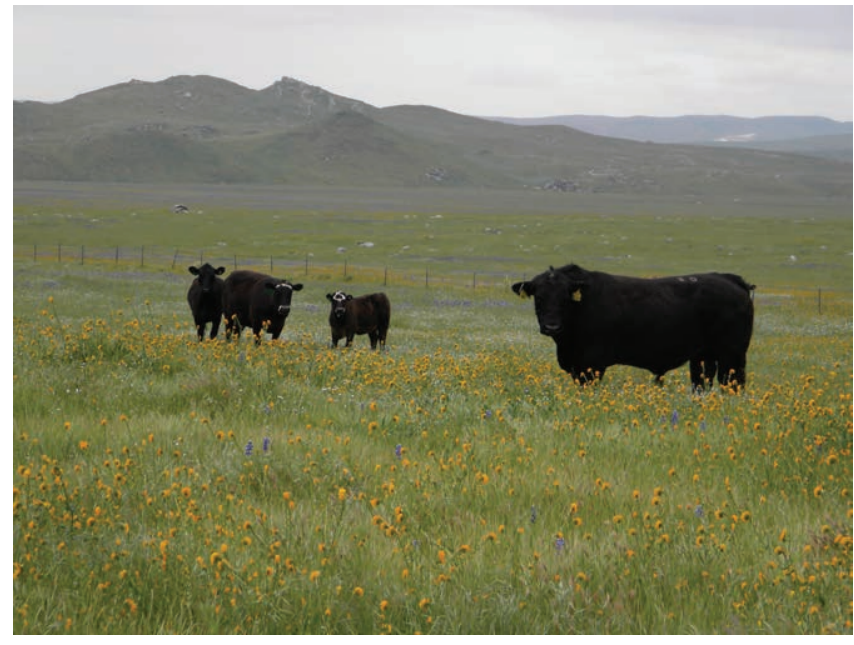

Figure 1. Cattle grazing a mix of non-native annual grasses and the conspicuous native annual forb fiddleneck (Amsinckia sp.) on Tejon Ranch grassland in the southern San Joaquin Valley. Photo by Rebecca Wenk.

bystoma californiense Gray) and other amphibians also use vernal pools.

In addition to these endemic species, serpentine grasslands and vernal pools provide "safe space" for many nonendemic native plants that are largely responsible for the two habitats' celebrated spring wildflower displays. The inhospitable growing conditions make it difficult for non-native grasses and forbs to flourish, so native species usually do not have to compete with them for resources.

That said, non-native plants have invaded both vernal pool and serpentine grasslands, despite the harsh growing conditions. Although most non-native species cannot grow in a vernal pool while it is wet, they can hug the boundary of a pool as it dries, competing with native wildflowers on the edges and increasing the evapotranspiration rate for the pool water. This has likely contributed to local losses of native fauna and flora. Most non-natives could not grow on serpentine soil until recently, but because of nitrogen deposited from car exhaust that fertilizes the soil, non-native annual grasses now dominate on serpentine grasslands near urban areas. Nonnative grass dominance has been convincingly implicated in the disappearance of butterfly populations, in part because of the greatly reduced abundance of their host plants.

Grassland biodiversity can be enhanced by livestock grazing at the landscape level by preserving open space and at the pasture level by influencing habitat structure. Cattle generally prefer grasses to forbs and so will eat non-native grass and leave the native forbs. Several studies have demonstrated that cattle grazing maintains native plant and animal biodiversity in vernal pools and on serpentine soils. ${ }^{7,8}$ In a vernal pool study, year-round grazing resulted in the highest cover of native plants and the longest period of water remaining in the pools. This effect appears to be primarily related to grazing intensity and reduction of residual dry matter that can favor non-native grasses. 


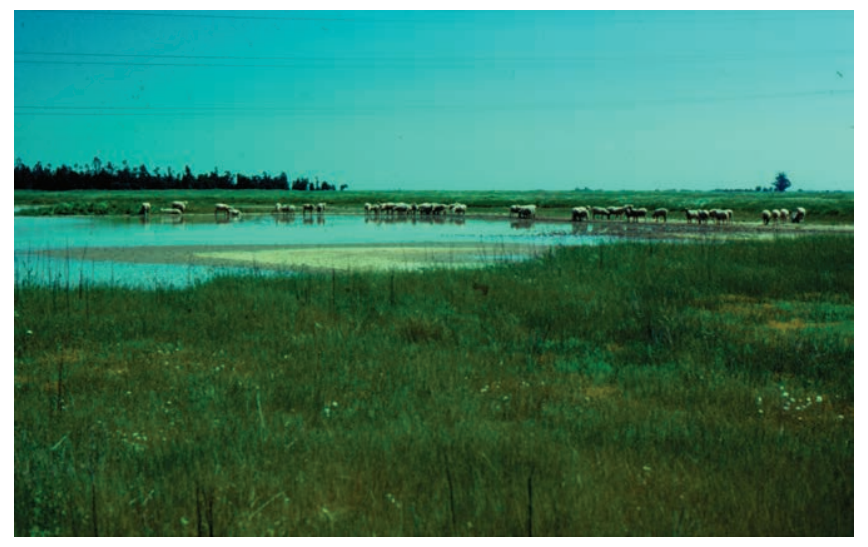

Figure 2. Sheep grazing at Olcutt Lake, a large vernal pool, during spring before it dries up in late summer. Photo by J. Bartolome.

\section{Wetlands and Riparian Systems}

Riparian ecosystems associated with streams and springs contribute to biodiversity of California's Mediterranean grasslands because they regulate the state's water quality and attract wildlife as well as livestock during certain seasons of the year (Fig. 2). Examples of direct relationships between grazing and biodiversity come from a handful of studies that show that the effects of grazing differ among stock ponds, vernal pools, and springs. More highly productive than surrounding grasslands, wetlands would be expected to show more of a grazing effect than the associated drier uplands.

Numerous spring-fed wetlands are nested within California's oak savanna-annual grassland landscape but until recently were not considered important in Californian range management. Depending on moisture supply, they may persist through the dry season and normally include an associated reach of creek. In a 10-year study comparing the effects of grazing removal with moderate and light grazing, moderate use reduced cover but significantly increased overall plant species richness, evenness, and diversity within pastures. ${ }^{9}$ There was no effect on the proportion of native and exotic plants. Grazing removal increased cover at springs, but not at associated creeks. The authors concluded that moderate grazing, which was applied in late spring, had a significant positive effect on biodiversity in creek riparian systems associated with springs and was a primary control on local stability and productivity.

\section{Vertebrates in San Joaquin Valley Grasslands}

The original structure and composition of vegetation communities in the San Joaquin Valley are uncertain; however, the current view is that before European settlement native perennial grasses likely dominated more mesic areas (riparian corridors) while annual forbs and shrubs likely dominated drier areas. Vertebrate species that evolved in these arid habitats appeared to prefer low-biomass conditions characteristic of forb-dominated annual grasslands, and habitat quality can be adversely affected by high biomass conditions that result when Mediterranean annual grasses dominate. A number of these vertebrates are considered special status species by federal and state of California agencies, including the San Joaquin kit fox (Vulpes macrotis Merriam), giant kangaroo rat (Dipodomys ingens Merriam), and blunt-nosed leopard lizard (Gambella sila Stenjnger). Thus grazing management to maintain low biomass conditions has been proposed as a way to mitigate adverse effects of Mediterranean annual grasses.

For the southern San Joaquin Valley where conservation of special status vertebrate species is a priority, a typical goal is to manage habitat so that $\leq 1,000 \mathrm{lb} / \mathrm{acre}(1,140 \mathrm{~kg} / \mathrm{ha})$ of residual dry matter (RDM) remains at the end of the growing season, preferably an RDM of $\leq 500 \mathrm{lb} / \mathrm{acre}(570 \mathrm{~kg} /$ ha). Other objective metrics include vegetation height and percent ground cover. For example, a maximum herbaceous vegetation height of $20 \mathrm{~cm}$ ( 8 in) has been proposed for San Joaquin kit foxes, and 15-30\% ground cover has been suggested as optimal for blunt-nosed leopard lizards.

Experimental evaluation of these grazing management targets is limited. In a 10-year grazing study where grazing was managed to maintain RDM at $\leq 500 \mathrm{lb} / \mathrm{acre}(570 \mathrm{~kg} / \mathrm{ha}$ ), the abundance of blunt-nosed leopard lizard and several small mammals was higher in grazed plots (RDM range 127-663 $\mathrm{lb} / \mathrm{acre}[145-760 \mathrm{~kg} / \mathrm{ha}])$ than ungrazed plots (RDM range 894-1,572 lb/acre [1,020-1,790 kg/ha]). ${ }^{10}$ In long-term studies on the Elkhorn Plain in the 1980s and 1990s, grazing did not appear to affect abundance of giant kangaroo rat or blunt-nosed leopard lizard, although giant kangaroo rats declined to a lesser extent on grazed areas during periods of high precipitation and vegetation density (California State University, Stanislaus, Endangered Species Recovery Program, unpublished data). In one study on the Carrizo Plain National Monument, grazing by cattle (Bos spp.) and giant kangaroo rats reduced RDM to about $305 \mathrm{lb} / \mathrm{acre}(350 \mathrm{~kg} /$ ha) by autumn, but cattle grazing did not appreciably affect the percent cover of either native or non-native plants. However, abundance of giant kangaroo rats tended to be higher in grazed areas during years of high precipitation and primary productivity.

\section{Ohlone Tiger Beetle}

The endangered Ohlone tiger beetle (OTB) (Cicindela oblone Freitag and Kavanaugh) is endemic to coastal prairie habitats on former marine terraces with Watsonville Loam soils and now persists only in northern Santa Cruz County, CA. Habitat quality depends on animal grazing effects (or their simulation) to maintain bare or sparsely vegetated soil surfaces for larval burrows, feeding, and adult mating and ovipositing. OTB has been extirpated from about half of its 17 known sites due to urbanization, fragmentation, and other unfavorable changes in habitat conditions and management.

Habitat at the extant OTB sites is also threatened by colonization of non-native perennial grasses and absence of wildfire. Habitat quality is diminished by elevated plant density and thatch, but can be managed effectively with repeated livestock grazing and bicycle or vehicle traffic. OTB occupied 
livestock and recreational trails had $>50 \%$ cover of bare soil, while off-trail grasslands had $>12 \%$ bare soil. ${ }^{11}$ Occupied offtrail sites also had high forb cover, low litter cover and depth, and high soil bulk density. ${ }^{12}$ Because the amount of bare soil in grassland habitat is very dependent on annual weather conditions and season, the effects of livestock grazing, livestock trailing, and other management treatments are likely to be most important during years with weather favorable to herbaceous growth. Population viability at OTB sites managed with grazing was higher than at those managed without grazing. ${ }^{13}$ Because the amount of sunlit, bare soil is so important for OTB habitat quality, management should be focused on maintaining and expanding those types of conditions. Control of non-native perennial grasses by grazing and other means should be another high priority for sites with potential OTB habitat (Fig. 3).

\section{Red-Legged Frog and California Tiger Salamander}

Two federally listed amphibian species, California tiger salamander (CTS) and California red-legged frog (CRLF) (Rana draytonii Baird and Girard), occur in California rangelands. CTS and CRLF breed in ephemeral or permanent pools in rangelands, and CRLF also breeds in slow-moving creeks. Dispersal through upland environments is important for these species, and both CTS and CRLF are known to move great distances from their breeding grounds to upland locations that provide moisture and cover during California's hot, dry summer and fall. While CRLF may reside in densely vegetated springs or creeks during this period, both species will use, and CTS is dependent on, small mammal burrows (especially those of California ground squirrel (Spermophilus beecheyi Richardson).$^{14}$

Livestock management potentially influences all life stages of CTS and CRLF and is generally considered beneficial for their conservation. A major factor contributing to the conservation of these two species in rangelands is the use of stock ponds for their breeding. Additionally, by reducing the above-ground biomass accumulated by annual grasses, cattle grazing can facilitate CTS and CRLF movement and dispersal. California ground squirrels tend to increase in areas with cattle grazing, which in turn creates more upland burrow habitat essential for CTS and CRLF. ${ }^{14}$ While the effects of cattle grazing on dispersal and abundance of CTS and CRLF are mainly observational and need to be verified experimentally, cattle grazing is recommended as a conservation tool for managing these species.

\section{Grassland Birds}

The diversity of grassland birds in California may benefit from livestock grazing directly and indirectly at many scales. Horned larks (Eremophila alpestris L.) prefer livestock-grazed grasslands for breeding habitat in both California and Midwestern prairies. ${ }^{15}$ Herbivory and trampling of cattle likely replaces native grazers such as Tule elk and creates ideal nest-
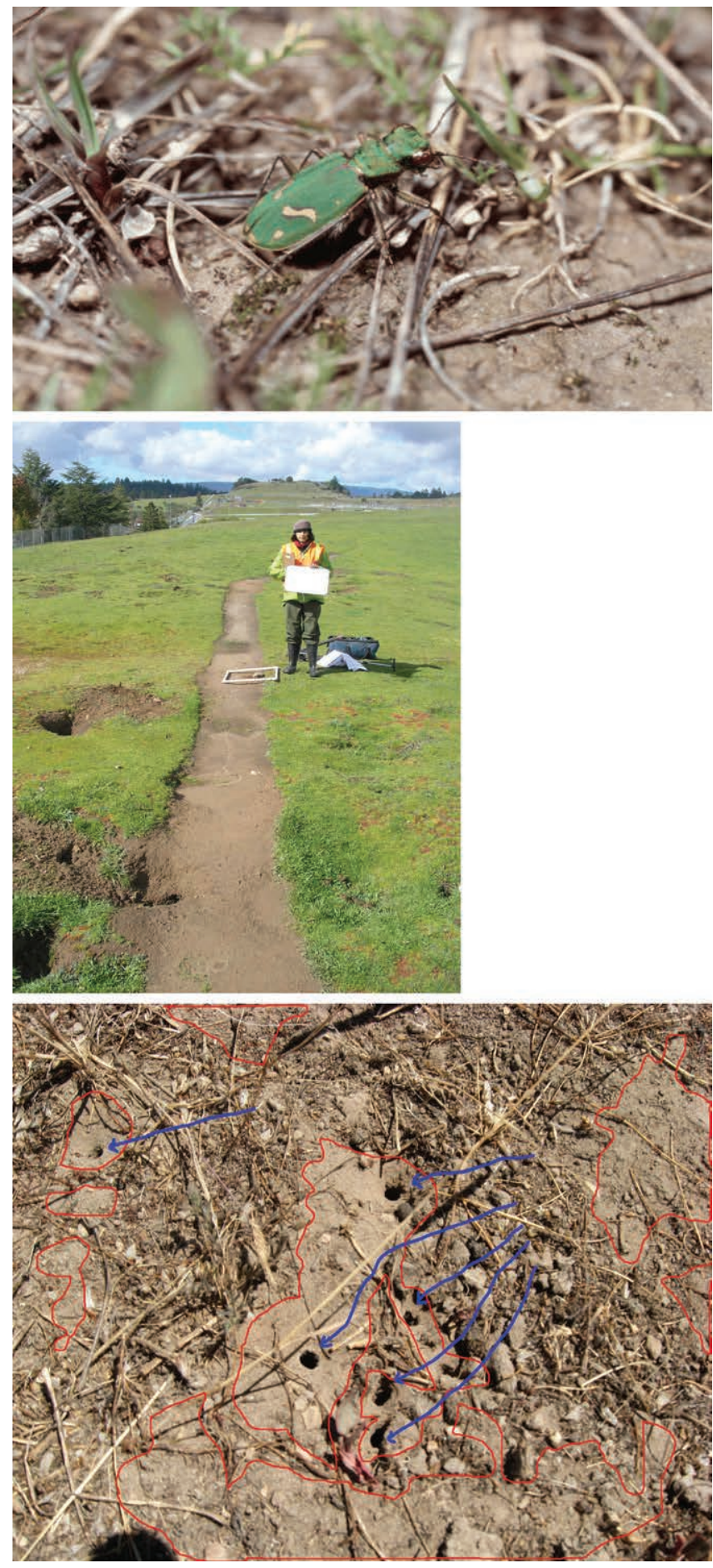

Figure 3. The federally listed endangered Ohlone tiger beetle and its required habitat. The predatory larvae live for up to three years in burrows strongly associated with bare ground. Photos by R. Arnold (adult beetle) and L. Ford.

ing areas of bare soil and short grassland vegetation for the horned lark. Californian native grassland areas with a mix of bunchgrasses and annual wildflowers have this varied vegetation structure, and moderate intensity cattle grazing can help 
create and maintain this structure on sites dominated by nonnative annual grasses.

Removing grazing from a ranch or preserve could have negative consequences for foraging grassland hawks in the Central Valley. ${ }^{16}$ Ferruginous hawks (Buteo regalis G. R. Gray) spend the winter in high numbers in grazed, open grassland, which provides short vegetation and a denser community of California ground squirrels. From a landscape perspective, however, grassland birds respond to the size of the grassland and its surrounding matrix of land-use types as well as smaller-scale grazing effects. ${ }^{15}$ Larger patches of open grassland support a more species-rich, abundant grassland bird community. The ranching industry contributes the majority of this habitat in California by providing foraging and breeding habitat for grassland birds as well as preventing grassland fragmentation and loss to urban development or intensive agriculture.

\section{Conclusions and Recommendations}

The examples presented above are representative of the published literature on grazing for biodiversity, measured as native species richness and/or abundance, and illustrate both the complexity of Mediterranean grasslands and applied grazing management. Most studies included multiple spatial and temporal scales, but rarely as an explicit part of the research design; most also included temporal replication. However, considerable research needs to be done to fully understand the effects of various grazing treatments.

Studies of native grasses, native forbs, vernal pools, serpentine, and wetlands showed differing effects of grazing on diversity. In the case of native perennial grasses, the primary problem is a conservation goal based on misinformation about their abundance and distribution prior to European contact and the role of grazing in both their demise and recovery. Researchers are beginning to better understand the role of native annual plants; however, taxon- and site-specific management trials are needed. Without better information about site potential at the pasture level and associated weather effects, the results of any specific grazing treatment will be difficult to predict. Serpentine and vernal pool ecosystems have shown promising responses to livestock grazing for increasing landscape level diversity and reducing exotic plant species; however, the number of published examples is still very small. For both ecosystems the primary goal of grazing is to reduce accumulated residual dry matter. Other wetland ecosystems also show considerable promise for the use of grazing to promote native species diversity and ecosystem function and, unlike other reviewed ecosystem types, show promise for management of seasonal grazing use with more practical testing and verification.

Faunal diversity in part depends on the diversity, composition, and structure of the vegetation and, therefore, on a better understanding of grazing effects. Despite the limitations referred to above, some simple and practical grazing prescriptions have shown promise. Management of grazing to reduce height and RDM and increase bare ground to favor listed vertebrates in the San Joaquin Valley is based on limited evidence, but is ready for more application and management trials. Likewise for the Ohlone tiger beetle, red-legged frog, and California tiger salamander, enough is known to recommend grazing as beneficial for those target species and, therefore, biodiversity. Those recommendations are primarily based on levels of utilization; there is observational evidence for the effectiveness of seasonal use to improve habitat quality, but evidence for the habitat value of rotational grazing management is lacking. Finally, for grassland birds, evidence for landscape-level impacts of land use and a positive effect of grazing on grassland obligate species such as the horned lark are promising.

California's Mediterranean-type grassland ecosystems have a very complex evolutionary history and a record of changing management goals, reflected in recent redesignations of listed species of both plants and animals as positively affected by livestock grazing based on management experience. ${ }^{17}$ Probably the best way to summarize grazing for biodiversity on California's Mediterranean grasslands is that livestock grazing appears compatible with biodiversity, but a greater understanding of the underlying site factors and site potential will be necessary for reliable prediction of management effects. The better evidence of links between grazing and native species diversity is mainly through grazing intensity; other aspects of grazing are much more difficult to confirm. Serious suggestions have been made to restore Pleistocene levels of faunal diversity, including extinct large herbivores and predators. But for now, livestock grazing is proving both a useful buffer against development and a practical method for enhancing native biodiversity.

\section{References}

1. Allen-Diaz, B. 2000. Biodiversity is critical to future health of California's ecology and economy. California Agriculture 54:26-34.

2. Edwards, S. W. 2004. Paleobotany of California. Four Seasons 12:3-75.

3. Huntsinger, L., and J. W. Bartolome. 2014. Cows? In California? Rangelands and livestock in the golden state. Rangelands 36(5):4-10.

4. Spiegal, S., L. Larios, J. W. Bartolome, and K. N. Suding. 2014. Restoration management for spatially and temporally complex Californian grassland. In: P. Mariotte, and P. Kardol [EDS.]. Grasslands: biodiversity and conservation in a changing world. Hauppauge, NY, USA: Nova Science Publishers. p. 69-104.

5. Evett, R. R., And J. W. Bartolome. 2013. Phytolith evidence for the extent and nature of prehistoric Californian grasslands. The Holocene 23:1644-1649.

6. Stahlheber, K. A., and C. M. D’Antonio. 2013. Using livestock to manage plant composition: a meta-analysis of grazing in California Mediterranean grasslands. Biological Conservation 157:300-308. 
7. Weiss, S. B. 1999. Cars, cows, and checkerspot butterflies: nitrogen deposition and management of nutrient-poor grasslands for a threatened species. Conservation Biology 13:14761486.

8. Marty, J. T. 2005. Effects of cattle grazing on diversity in ephemeral wetlands. Conservation Biology 19:1626-1632.

9. Jackson, R. D., and B. Allen-Diaz. 2006. Spring-fed wetland and riparian plant communities respond differently to altered grazing intensity. Journal of Applied Ecology 43:485-498.

10. Germano, D. J., G. B. Rathbun, and L. R. Saslaw. 2012. Effects of grazing and invasive grasses on desert vertebrates in California. Journal of Wildlife Management 76:670-682.

11. Knisley, C. B., And R. A. Arnold. 2013. Biology and conservation of Cicindela oblone Freitag and Kavanaugh, the endangered Ohlone tiger beetle (Coleoptera: Carabidae: Cicindelinae). I. Distribution and natural history. Coleopterists Bulletin 67:569-580.

12. Cornelisse, T. M. 2013. Conserving extirpated sites: using habitat quality to manage unoccupied patches for metapopulation persistence. Biodiversity and Conservation 22:31713184.

13. Cornelisse, T. M., M. K. Bennett, and D. K. Letourneau. 2013. The implications of habitat management on the population viability of the endangered Ohlone tiger beetle (Cicindela oblone) metapopulation. PloS ONE 8:e71005.

14. Ford, L. D., P. A. Van Hoorn, D. R. Rao, N. J. Scott, P. C. Trenham, And J. W. Bartolome. 2013. Managing rangelands to benefit California red-legged frogs and California tiger salamanders. Livermore, CA, USA: Alameda County Resource Conservation District. 67 p.

15. Rao, D., S. Gennet, M. Hammond, P. Hopkinson, and J. BArtolome. 2008. A landscape analysis of grassland birds in a valley grassland-oak woodland mosaic. In: A. Merenlender, D. McCreary, and K. Purcell [tech. eds.]. Proceedings of the Sixth California Oak Symposium: today's challenges, tomorrow's opportunities. Albany, CA, USA: USDA Forest Service, General Technical Report PSW-GTR-217. p. 385-397.

16. Pandolfino, E. R., M. Herzog, S. Hooper, and Z. Smith. 2011. Winter habitat associations of diurnal raptors in California's Central Valley. Western Birds 42:62-84.

17. Barry, S. J. 2011. Current findings on grazing impacts of California's special status species. Keeping landscapes working. University of California Cooperative Extension 7:2-6.

18. Stein, B. A., L. S. Kutner, and J. S. Adams. 2000. Precious heritage: the status of biodiversity in the United States. New York, NY, USA: Oxford University Press. 399 p.

19. Myers, N., R. A. Mittermeier, C. G. Mittermeier, G. A. B. DA FonsecA, And J. Kent. 2000. Biodiversity hotspots for conservation priorities. Nature 403:853-858.
20. Noss, R. F., And R. L. Peters. 1995. Endangered ecosystems: a status report on America's vanishing habitat and wildlife. Washington, DC, USA: Defenders of Wildlife. $151 \mathrm{p}$.

21. Hoekstra, J. M., T. M. Boucher, T. H. Ricketts, and C. RoberTs. 2005. Confronting a biome crisis: global disparities of habitat loss and protection. Ecology Letters 8:23-29.

22. Peart, R. 2008. Life in a working landscape: towards a conservation strategy for the world's temperate grasslands: a record of the World Temperate Grasslands Conservation Initiative Workshop, Hohhot, China, 28 and 29 June 2008, Temperate Grasslands Conservation Initiative. Vancouver, British Columbia, Canada: International Union for Conservation of Nature and World Commission on Protected Areas.

23. Jantz, P. A., B. F. L. Preusser, J. K. Fujikawa, J. A. Kuhn, C. J. Bersbach, J. L. Gelbard, and F. W. Davis. 2007. Regulatory protection and conservation. In: M. R. Stromberg, J. D. Corbin, and C. M. D'Antonio [EDs.]. California grasslands: ecology and management. Berkeley, CA, USA: University of California Press. p. 297-318.

24. Standiford, R. B., J. Klein, And B. Garrison. 1996. Sustainability of Sierra Nevada hardwood rangelands. In: Status of the Sierra Nevada: Volume III Sierra Nevada Ecosystem project report. University of California Division of Agriculture and Natural Resources. Wildland Resources Center Report 38:637-680.

25. Weiss, S. B., D. H. Wright, and C. Niederer. 2007. Serpentine vegetation management project: final report to the United States Fish and Wildlife Service. Menlo Park, CA, USA: Creekside Center for Earth Observation. 42 p.

26. European Environment Agency. 2013. The European grassland butterfly indicator: 1990-2011. Luxembourg City, Luxembourg: European Environment Agency. EEA Technical Report $11 / 2013$.

27. Penrod, K., P. E. Garding, C. Paulman, P. Beier, S. Weiss, N. Schaefer, R. Branciforte, and K. Gaffney. 2013. Critical linkages: Bay area \& beyond. Fair Oaks, CA, USA: Science \& Collaboration for Connected Wildlands. 612 p.

Authors are Professor, jwbart@berkeley.edu (Bartolome), Professor (Allen-Diaz), Staff Research Associate (Hammond), Academic Coordinator (Hopkinson), Graduate Student Researcher (Ratcliff), and Graduate Student Researcher (Spiegal), Dept of Environmental Science, Policy and Management, University of California, Berkeley, CA 94720, USA; Natural Resources Advisor, Division of Agricultural and Natural Resources, University of California, San Jose, CA 95112, USA (Barry); Research Associate, University of California, Santa Cruz, CA 95064, USA (Ford); and Conservation Science Director, Tejon Ranch Conservancy, Lebec, CA 93243, USA (White). 